\title{
EVALUATION OF THE INFLUENCE OF DIFFERENT IMPLANT ANGULATIONS ON THE ACCURACY OF AN IMPRESSION RECORDED USING VARIOUS VISCOSITIES OF ADDITION SILICONE IMPRESSION MATERIAL-AN IN-VITRO STUDY
}

\author{
Dr. Reshma Babu ${ }^{1}$, Dr. Neelima Menon..$^{* 2}$ \\ ${ }^{1}$ Assistant Professor, Maruti Dental College, Bangalore, India \\ ${ }^{*_{2}}$ Assistant Professor, PSM College of Dental Sciences, Akkikkavu, Thrissur, India - 680519
}

\section{ABSTRACT}

INTRODUCTION: Implant with an axial orientation that is not in line with the needs of prosthetic rehabilitation may occur for various reasons. As a result, the impression procedure may be adversely influenced. Inaccuracies during impressions inevitably lead to laboratory errors resulting in lack of precision and misfit of the restoration.

AIM AND OBJECTIVES: The primary objective of the present study was to evaluate the comparative accuracy of pick-up impressions -mono phasic versus single stage/single stage double mix technique (multiple mix) of implants with different angulations and with a secondary objective to evaluate the effect of different viscosities of vinyl polysiloxane impression material on the accuracy of the impressions.

MATERIALS AND METHODOLGY: Four sets of two implant analogues were placed parallel to each other at various angulations at $0^{0,} 5^{0}, 10^{\circ}, 15^{\circ}$. Sample size -64 and $p$ value $<0.05$. Definitive impressions were made using vinyl polysiloxane of different consistencies with the following impression techniques. Soft putty body and light body, heavy body and light body, medium body and Bite registration along with soft putty body and light body.Profile projector was used to measure the distance between two reference points.

RESULT: It was seen that the accuracy of Putty -light body polysiloxane impression for parallel to 5 degrees, bite registration material-putty-light body polysiloxane impression for 5-10 degrees and heavy-light body polysiloxane impression for10-15 degree angulated implants impressions was higher. The $p$ value is $<0.05$ indicating that the above was statistically significant.

CONCLUSION: Through this study it can be concluded that higher angulations of the implants more force is required to retrieve the impression. Also, more viscous the impression material lesser the displacement of impression copings thus higher the accuracy of impression made.

Key words: Implant angulation, Impression copings, Dimensional accuracy, Dental impression material

\section{INTRODUCTION}

In dentistry, impression materials are used to record intraoral structures for the fabrication of definitive restorations. The accuracy of these restorations is highly dependent on the impression materials and techniques utilized.

Implant with an axial orientation that is not in line with the needs of prosthetic rehabilitation may occur for various reasons. These may adversely affect precision of the impression.

Hondrumet al stated that the accuracy,

${ }^{*}$ Corresponding author:

Email: drneelimaprosthodontist@gmail.com

http://dx.doi.org/10.20530/IJTA 33 145-153

ISSN 2320-138X (c) 2016 dimensional stability, and tear strength are the most critical properties. Wettability which is material's ability to spread over a surface, strongly affects the accuracy of an impression material. ${ }^{1}$

There are four groups of elastomeric impression materials polysulfides, polyethers, condensation and addition silicones. ${ }^{2}$ Addition silicone is widely used because of their excellent dimensional stability and their ability to reproduce impressions with accuracy and minimal distortion. ${ }^{3}$ Inaccuracies during impressions inevitably lead to laboratory errors resulting in lack of precision and misfit of the restoration. ${ }^{5}$

The high strain tolerance of the poly (vinyl siloxane) impression materials allows their removal without distortion from appreciable undercuts ${ }^{12}$. Viscosity characteristics of the impression rubbers were linked to filler content ${ }^{13}$. 
Table 1: Comparison of four materials in parallel condition

\begin{tabular}{lccc}
\hline Materials & Mean & SD & SE \\
\hline Reference cast & 16.064 & & \\
Putty light body & 16.173 & 0.017 & 0.010 \\
Medium body & 16.212 & 0.020 & 0.012 \\
Heavy body & 16.348 & 0.052 & 0.030 \\
Bite registration & 16.371 & 0.126 & 0.073 \\
H-value & & 8.7440 & \\
p-value & & $0.0330^{*}$ & \\
\hline
\end{tabular}

\begin{tabular}{|c|c|}
\hline Pair wise comparison & n-Whitney U tes \\
\hline Putty light body vs & \\
\hline Medium body & $P=0.0495^{*}$ \\
\hline Putty light body vs & \\
\hline Heavy body & $P=0.0495^{*}$ \\
\hline Putty light body vs & \\
\hline Bite registration & $P=0.0495^{*}$ \\
\hline Medium body vs & \\
\hline Heavy body & $P=0.0495^{*}$ \\
\hline Medium body vs Bite & \\
\hline registration & $P=0.1266$ \\
\hline Heavy body vs Bite & \\
\hline registration & $P=0.5127$ \\
\hline
\end{tabular}

${ }^{*} \mathrm{p}<0.05$

A passive fit in implant prosthesis provides additional retention to the prosthesis, reducing the stresses transmitted to the underlying implant. Absence of passive fit, leads to static loads which results in either physiologic adaption of the attachment apparatus or if beyond the adaptive capacity of the host may result in the traumatism. Since osseointergrated implants have no periodontal ligament, adverse forces generated by misfit of restoration may result in mechanical complications and biological complications. ${ }^{6}$

Several studies investigated the variables affecting the accuracy of the impression in implant prosthodontics, such as direct or indirect impression technique, use of different impression materials, splinting or surface treatment of impression copings, the relative implant angulations and the die material accuracy.

Studies suggest open-tray technique is more accurate than the closed-tray for completely edentulous patients, but for partially edentulous patients there seems to be no difference. The implant angulation affects the accuracy of implant
Table 2: Comparison of four materials in 5 degree condition

\begin{tabular}{|c|c|c|c|}
\hline Materials & Mean & SD & SE \\
\hline Reference cast & 17.989 & & \\
\hline Putty light body & 17.948 & 0.045 & 0.026 \\
\hline Medium body & 17.837 & 0.043 & 0.025 \\
\hline Heavy body & 18.063 & 0.060 & 0.034 \\
\hline Bite registration & 17.901 & 0.069 & 0.040 \\
\hline $\mathrm{H}$-value & & 8.9670 & \\
\hline $\mathrm{p}$-value & & $0.0300^{*}$ & \\
\hline \multicolumn{4}{|c|}{ Pair wise comparison by Mann-Whitney $U$ tes } \\
\hline \multicolumn{4}{|c|}{ Putty light body vs } \\
\hline \multicolumn{2}{|c|}{$\begin{array}{l}\text { Medium body } \\
\text { Putty light body vs }\end{array}$} & \multicolumn{2}{|c|}{$P=0.0495^{*}$} \\
\hline \multicolumn{2}{|c|}{ Putty light body vs } & \multicolumn{2}{|c|}{$P=0.0495^{*}$} \\
\hline \multicolumn{2}{|c|}{ Bite registration } & \multicolumn{2}{|c|}{$P=0.2752$} \\
\hline \multicolumn{2}{|l|}{ Heavy body } & \multicolumn{2}{|c|}{$P=0.0495^{*}$} \\
\hline \multicolumn{2}{|c|}{$\begin{array}{l}\text { Medium body vs Bite } \\
\text { registration }\end{array}$} & \multicolumn{2}{|c|}{$P=0.1904$} \\
\hline \multicolumn{2}{|c|}{$\begin{array}{l}\text { Heavy body vs Bite } \\
\text { registration }\end{array}$} & \multicolumn{2}{|c|}{$\mathrm{P}=0.0495^{*}$} \\
\hline
\end{tabular}

impressions ${ }^{11}$ Situations in 3 or fewer implants, no difference between the pick-up and transfer techniques, whereas for 4 or more implants, higher accuracy with the pick-up technique ${ }^{15}$.

Several techniques have been proposed to reduce the distortion of the implant-supported framework, such as electrical discharge machining, the laser welding procedures, the computer numeric-controlled milled titanium frameworks and the computer aided design and-computer-aided manufacturing technologies. ${ }^{6}$

Most of the in-vitro studies evaluated how to improve the impression accuracy in ideal conditions, with parallel implants, fewer investigations were performed to assess the effect of nonparallel implants on the final precision of the impression and the effect of various viscosities of impression materials and its effect on the accuracy of the impression.

The purpose of the present study was to evaluate the comparative accuracy of pick-up impression of implants with different angulations using different 
Table 3: Comparison of four materials in 10 degree condition

\begin{tabular}{|c|c|c|c|}
\hline Materials & Mean & SD & SE \\
\hline Reference cast & 18.096 & & \\
\hline Putty light body & 18.363 & 0.082 & 0.048 \\
\hline Medium body & 18.519 & 0.026 & 0.015 \\
\hline Heavy body & 18.419 & 0.027 & 0.015 \\
\hline Bite registration & 18.090 & 0.039 & 0.022 \\
\hline $\mathrm{H}$-value & & 9.4620 & \\
\hline$p$-value & & $0.0240 *$ & \\
\hline \multicolumn{4}{|c|}{ Pair wise comparison by Mann-Whitney $U$ test } \\
\hline $\begin{array}{l}\text { Putty light body } \\
\text { Medium body } \\
\text { Putty light body }\end{array}$ & & \multicolumn{2}{|c|}{$P=0.0495^{*}$} \\
\hline $\begin{array}{l}\text { Heavy body } \\
\text { Putty light body }\end{array}$ & & \multicolumn{2}{|c|}{$P=0.5127$} \\
\hline $\begin{array}{l}\text { Bite registration } \\
\text { Medium body vs }\end{array}$ & & \multicolumn{2}{|c|}{$P=0.0495^{*}$} \\
\hline Heavy body & & \multicolumn{2}{|c|}{$P=0.0495^{*}$} \\
\hline $\begin{array}{l}\text { Medium body vs } \\
\text { registration }\end{array}$ & & \multicolumn{2}{|c|}{$P=0.0495^{*}$} \\
\hline $\begin{array}{l}\text { Heavy body vs } \mathrm{Bi} \\
\text { registration }\end{array}$ & & \multicolumn{2}{|c|}{$P=0.0495^{*}$} \\
\hline
\end{tabular}

viscosities of vinyl polysiloxane impression material. The null hypothesis tested in this study: There would be no significant differences in the accuracy of the implant impressions among the groups with different angulations of implants with $p$-value $<0.05$.

\section{MATERIALS AND METHODS}

A sample size of sixty four impressions was undertaken for this study. They were divided into four groups based on the angulations. Each group further consisted of sixteen such impressions. Eight

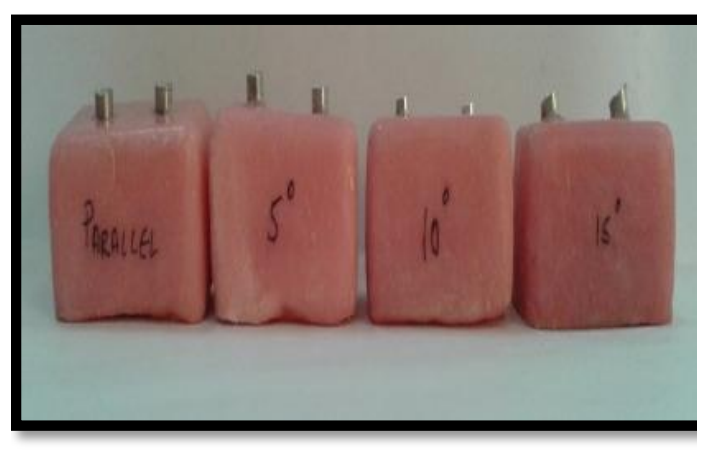

Figure 1: Implant Analogues of Various Angulation $\left(0^{\circ}, 50,100,150\right)$ Fixed In Resin Blocks
Table 4: Comparison of four materials in 15 degree condition

\begin{tabular}{|c|c|c|c|}
\hline Materials & Mean & SD & SE \\
\hline Reference cast & 18.471 & & \\
\hline Putty light body & 18.188 & 0.061 & 0.035 \\
\hline Medium body & 18.725 & 0.024 & 0.014 \\
\hline Heavy body & 18.301 & 0.023 & 0.013 \\
\hline Bite registration & 18.630 & 0.089 & 0.051 \\
\hline $\mathrm{H}$-value & & 9.9740 & \\
\hline $\mathrm{p}$-value & & $0.0190 *$ & \\
\hline \multicolumn{4}{|c|}{ Pair wise comparison by Mann-Whitney U test } \\
\hline \multicolumn{4}{|c|}{ Putty light body vs } \\
\hline \multicolumn{2}{|c|}{$\begin{array}{l}\text { Medium body } \\
\text { Putty light body vs }\end{array}$} & \multicolumn{2}{|c|}{$P=0.0495^{*}$} \\
\hline \multicolumn{2}{|l|}{ Heavy body } & \multicolumn{2}{|c|}{$P=0.0495^{*}$} \\
\hline \multicolumn{2}{|l|}{$\begin{array}{l}\text { Bite registration } \\
\text { Medium body vs }\end{array}$} & \multicolumn{2}{|c|}{$P=0.0495^{*}$} \\
\hline \multicolumn{2}{|l|}{ Heavy body } & \multicolumn{2}{|c|}{$P=0.0495^{*}$} \\
\hline \multicolumn{2}{|c|}{$\begin{array}{l}\text { Medium body vs Bite } \\
\text { registration }\end{array}$} & \multicolumn{2}{|c|}{$P=0.1266$} \\
\hline \multicolumn{2}{|c|}{ Heavy body vs Bite } & \multicolumn{2}{|c|}{$\mathrm{P}=0.0495^{*}$} \\
\hline
\end{tabular}

implant lab analogues were employed to replicate the implant positions, embedded in auto polymerizing resin.

Four sets of two implant analogues were placed parallel to each other at various angulations at $0^{0,} 5^{0}$ $, 10^{\circ}, 15^{\circ}$. The angles were drawn by means of plastic semicircular measuring instrument and held together by auto-polymerizing resin.

Two parallel holes were drilled in the rectangular resin block. The implants are placed parallel as when observed along midline mesial of one implant is angulated and other implant angulated distally. Each pair of implant analogues were fixed on to the resin block(reference specimen) with auto-polymerizing resin (Fig 1).

Two layers of modeling wax were adapted on to the reference specimen as spacer to standardize the thickness of impression material for all viscosities.

A total of sixty four custom impression trays (open trays) were fabricated using auto-polymerizing resin age soaked for 24 hours (Fig 2a, 2b). 


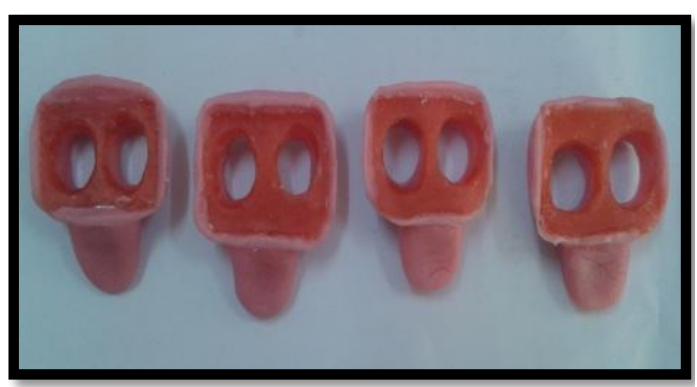

Figure 2a: Custom Impression Trays (Intaglio Surface)

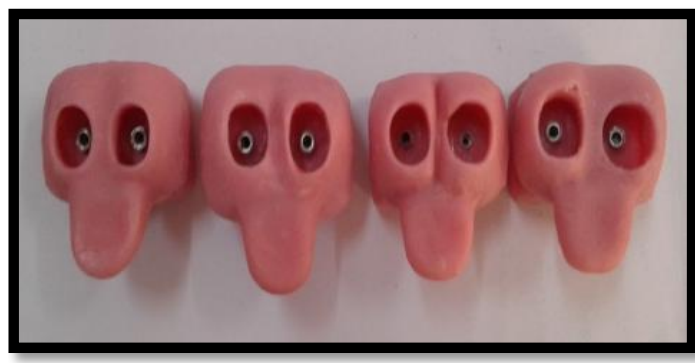

Figure 2b: Custom Impression Trays (Cameo Surface)

Tray adhesive was applied 15 minutes prior to

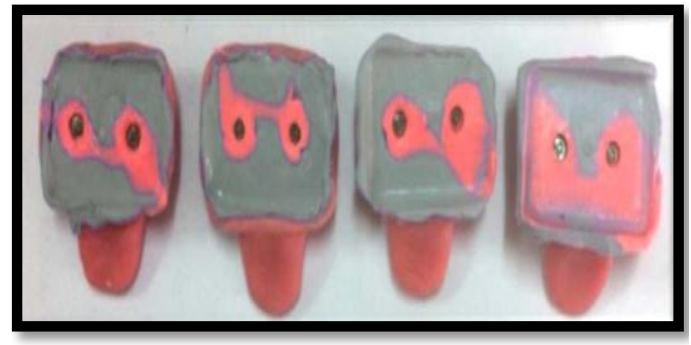

Figure 5: Heavy Body+Light Body

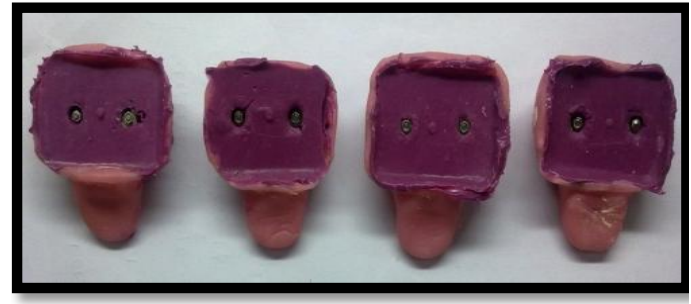

Figure: 6: Medium Body

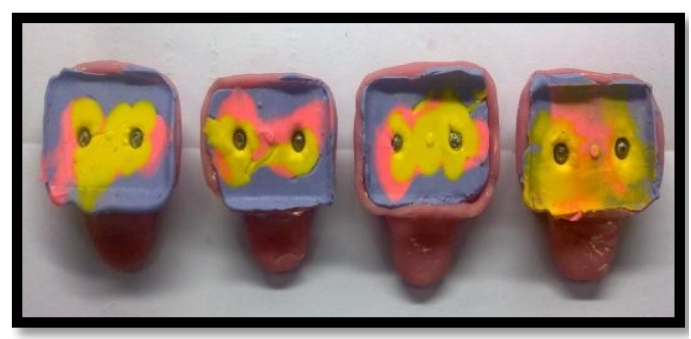

Figure: 7: Bite Registration +Soft Putty Body+ Light Body

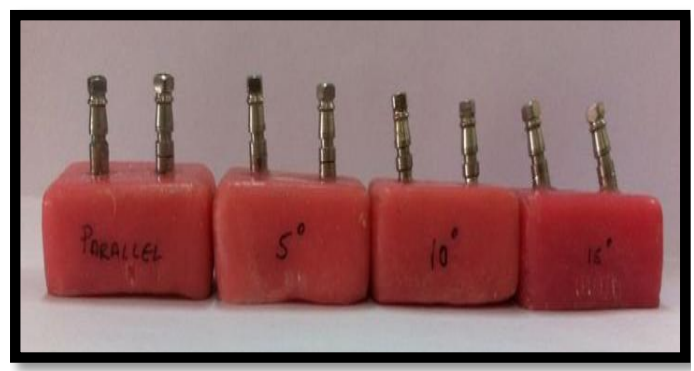

Figure 3: Impression Coping Placement Done On Various Angulation of Lab Analogues.

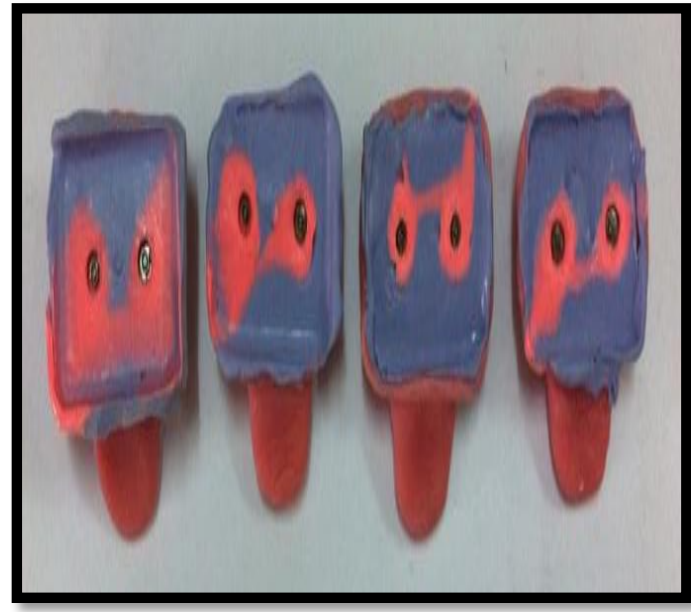

Figure 4: Soft Putty Body+Light Body

impression procedure .Impression copings were screwed over the implant analogues (Fig 3).Definitive impressions were made using vinyl polysiloxane(DENTSPLY) of different consistencies with the following impression techniques.

- Soft puttybody+light body(Fig 4)

- Heavybody+light body(Fig 5)

- Medium body(Fig 6)

- Bite registration+soft putty body+light body (Fig 7)

Light body impression material will accurately record the finer details and putty material will support the light body. All the impression materials were manipulated according to the manufacturer's instructions.

Three set of impressions were made using single stage technique, single stage-double mix technique on each reference model.

Once set, the impression material was trimmed at the border of the tray before removal to allow boxing of the impressions during pouring. The reference specimen was gently separated from the 

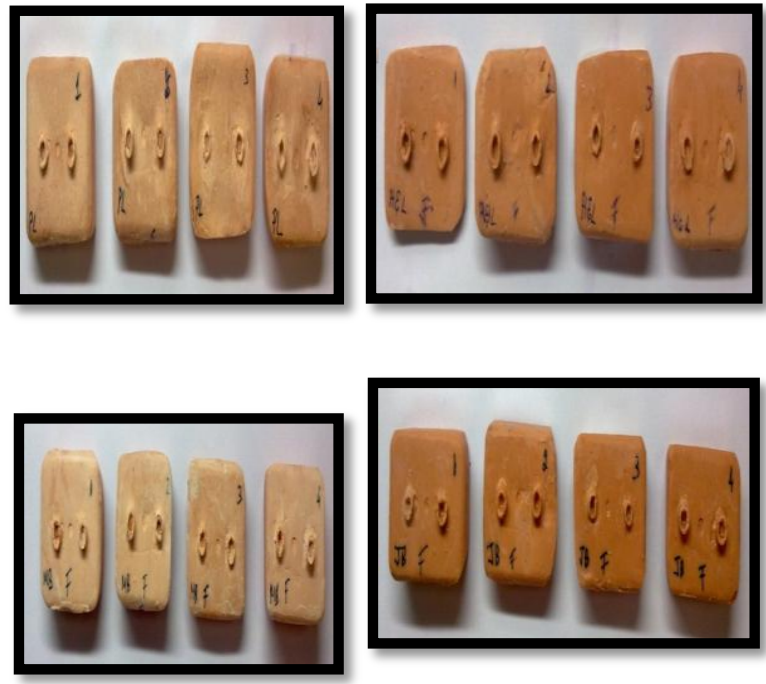

Figure: 8: casts obtained from four different impression techniques. 8a (Soft Putty Body + Light Body), 8b (Heavy Body + Light Body), 8c (Medium Body), 8d (Bite Registration + Soft Putty Body + Light Body).

impression. Once the impression material set the impression copings(square) were exposed with the means of blade, unscrewed using hex drive(open tray technique) so they remained in the impression when the tray was gently separated from the reference specimen.

Sixty minutes after the impression procedure, the impressions were boxed and cast with die stone -Type IV (Fig 8) and manipulated according to the manufacturer's instructions.

All the steps including manipulation of impression material, loading the impression material to the tray, loading the disposable syringe, injecting the impression material around the copings, seating the tray on the reference specimen and allowing the impression material to set,all were performed by single operator.

\section{Measurement procedure:}

The study was designed as single blind: all measurements were made by a single calibrated examiner. A profile projector was used to measure linear distances (Fig 9) ${ }^{5}$. Each model was secured in the holder of the device. Profile projector was provided with a screen with horizontal and vertical reference lines to allow adjusting all models to identical standardized positions, in order to ensure that the copings of all models were at the same level

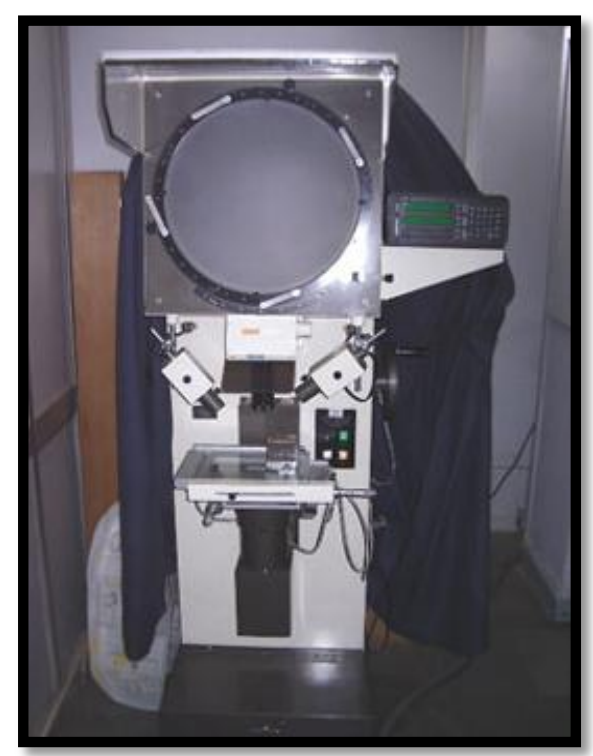

Figure 9: Profile Projector

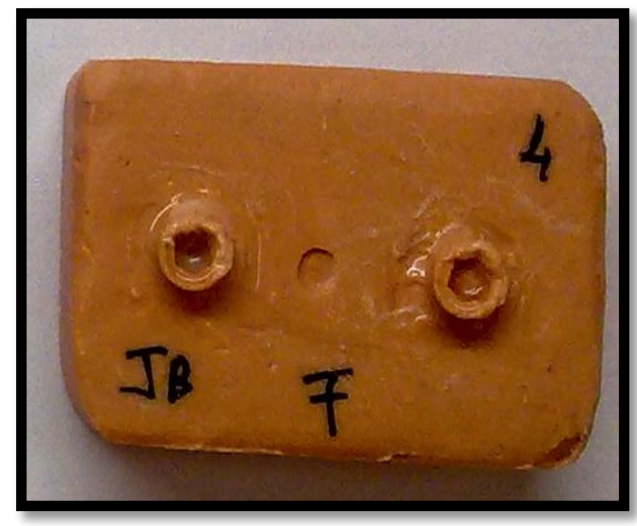

Figure 10: Marked reference points

during the measurements. Two reference points (Fig 10) for the two implant analogues respectively were marked at the point where the inner diameter and the floor formed by the impression coping meet measured in millimeters.

In the present study, distortion values were determined measuring the absolute values of such distances between the reference specimen and the models obtained.

The mean values described were considered for the statistical analysis. Comparison of four materials in different conditions $\left(0^{\circ}, 50,100,150\right)$ by Kruskal Wallis ANOVA test. Pair wise comparison was done by Mann-Whitney $U$ test. For all the statistical tests, the level of significance was set at $p<0.05$. 


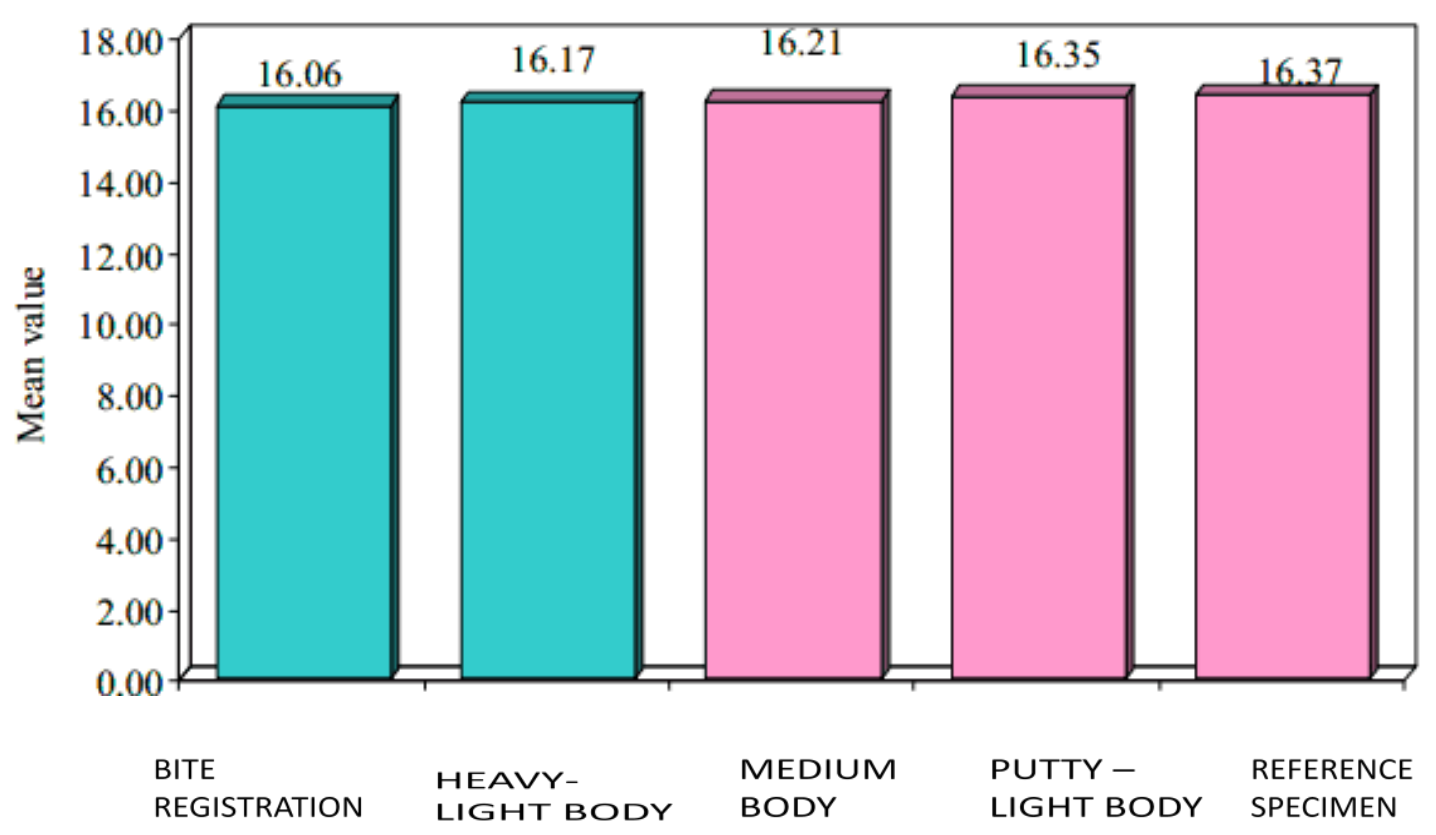

TABLE 1: COMPARISON OF FOUR MATERIALS WITH REFERENCE SPECIMEN IN PARALLEL CONDITION (mean values in millimeters)

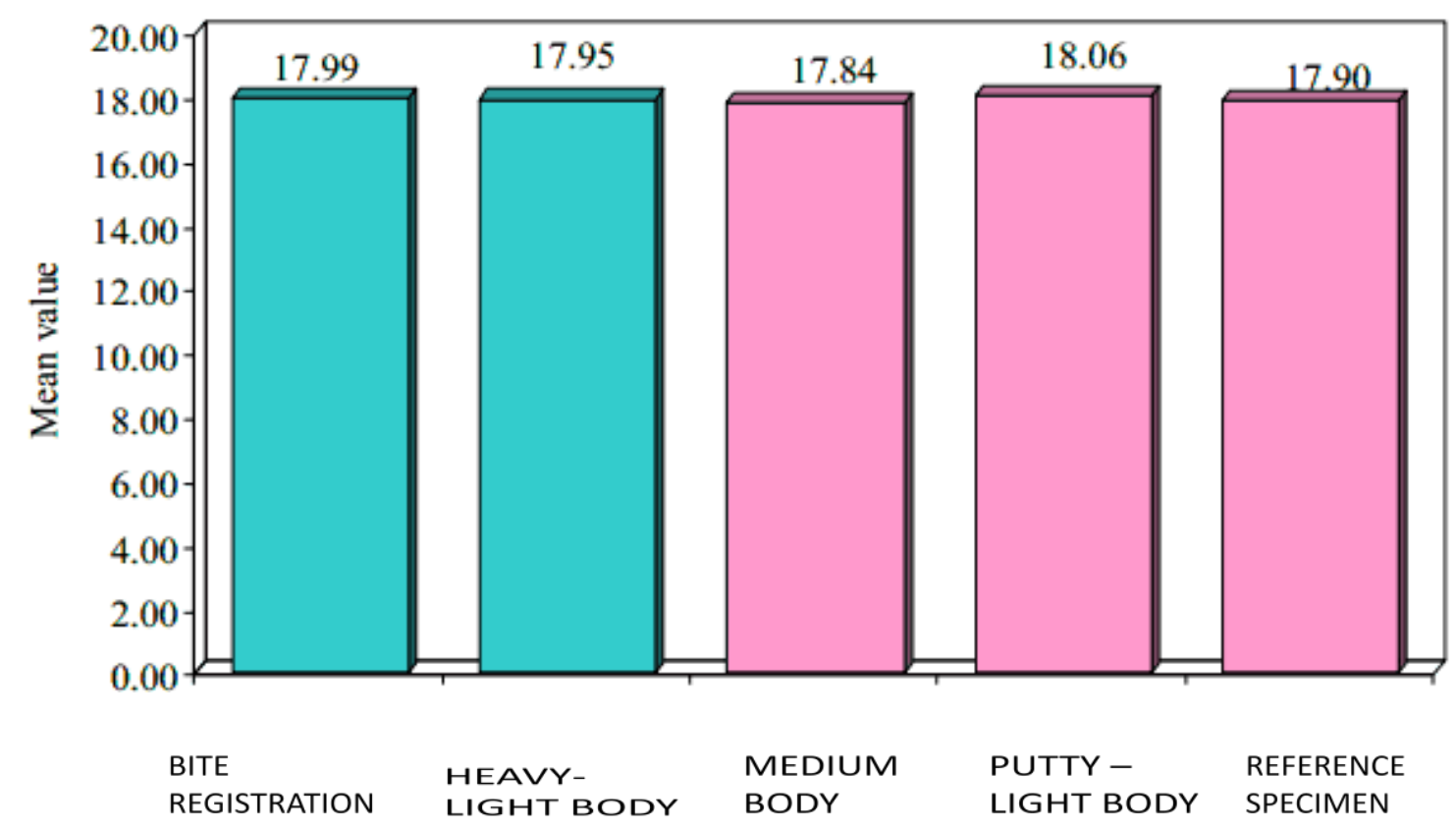

TABLE 2: COMPARISON OF FOUR MATERIALS WITH REFERENCE SPECIMEN IN 5 DEGREE ANGULATED CONDITION (mean values in millimeters)

\section{RESULTS}

The absolute control values obtained on the reference specimen (control model) and the mean linear measurements and standard deviations of the position of impression copings on the models are reported in Table 1, 2, 3,4 and graphical representation Figure $11,12,13$ and 14 respectively. Comparison of four materials in parallel condition, 5 , 10 and 15 degree angulation, Soft putty body and 


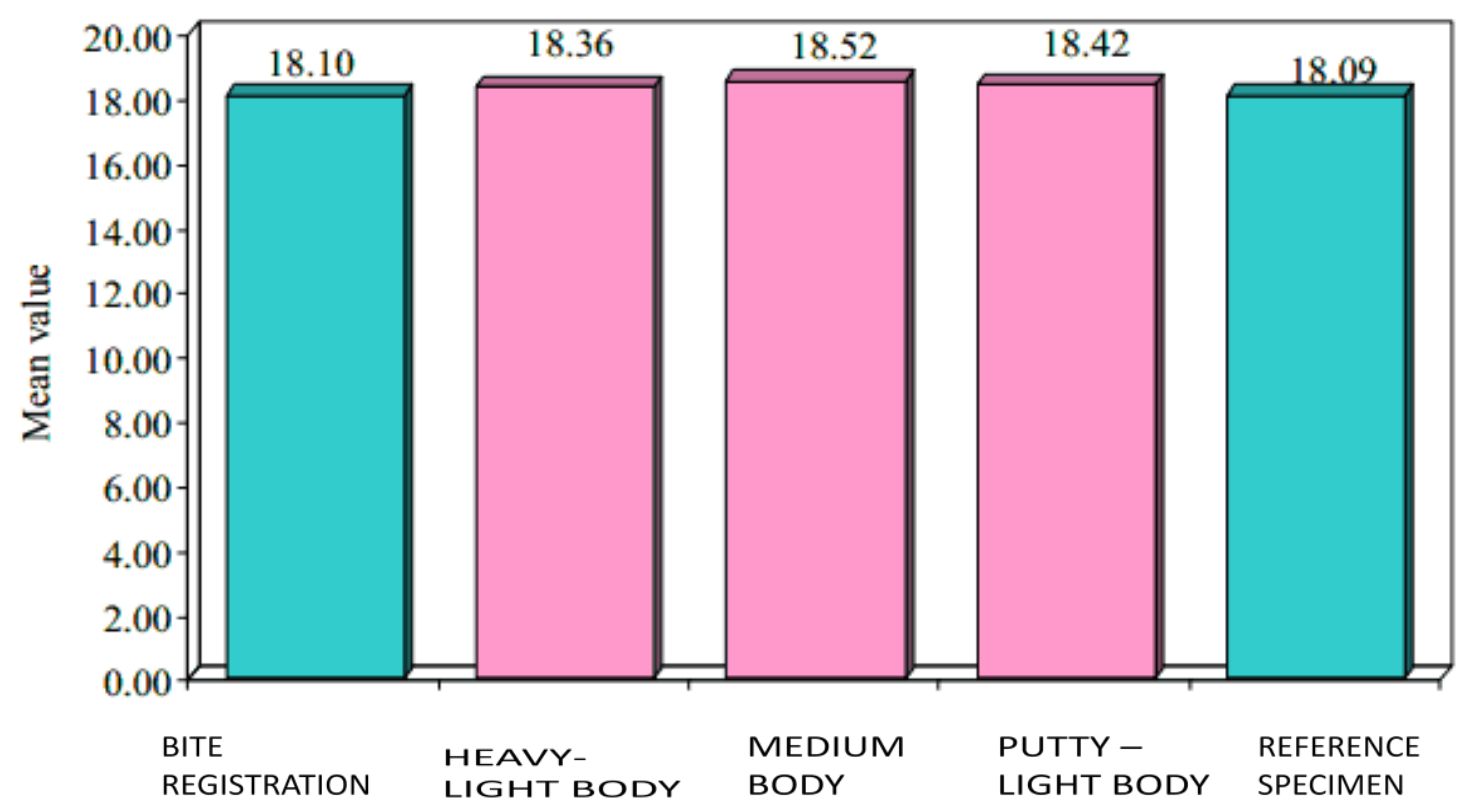

TABLE 3: COMPARISON OF FOUR MATERIALS WITH REFERENCE SPECIMEN IN 10 DEGREE ANGULATED CONDITION (mean values in millimeters)

light body, heavy body and light body, Medium body and also Bite registration with soft putty body and light body.

\section{DISCUSSION}

In implant prosthodontics, making a cast reproducing the intraoral position of implants and abutments as accurately as possible is important, in order to limit discrepancies in fit, including those not clinically detectable by visual inspection.

Clinically when the angulations of implants are unavoidable due to various reasons, prosthetic rehabilitation becomes challenging. Beginning with impression procedures, path of retrieval of the impression may be affected when multiple implants of different angulations present hence impression material and impression technique which causes

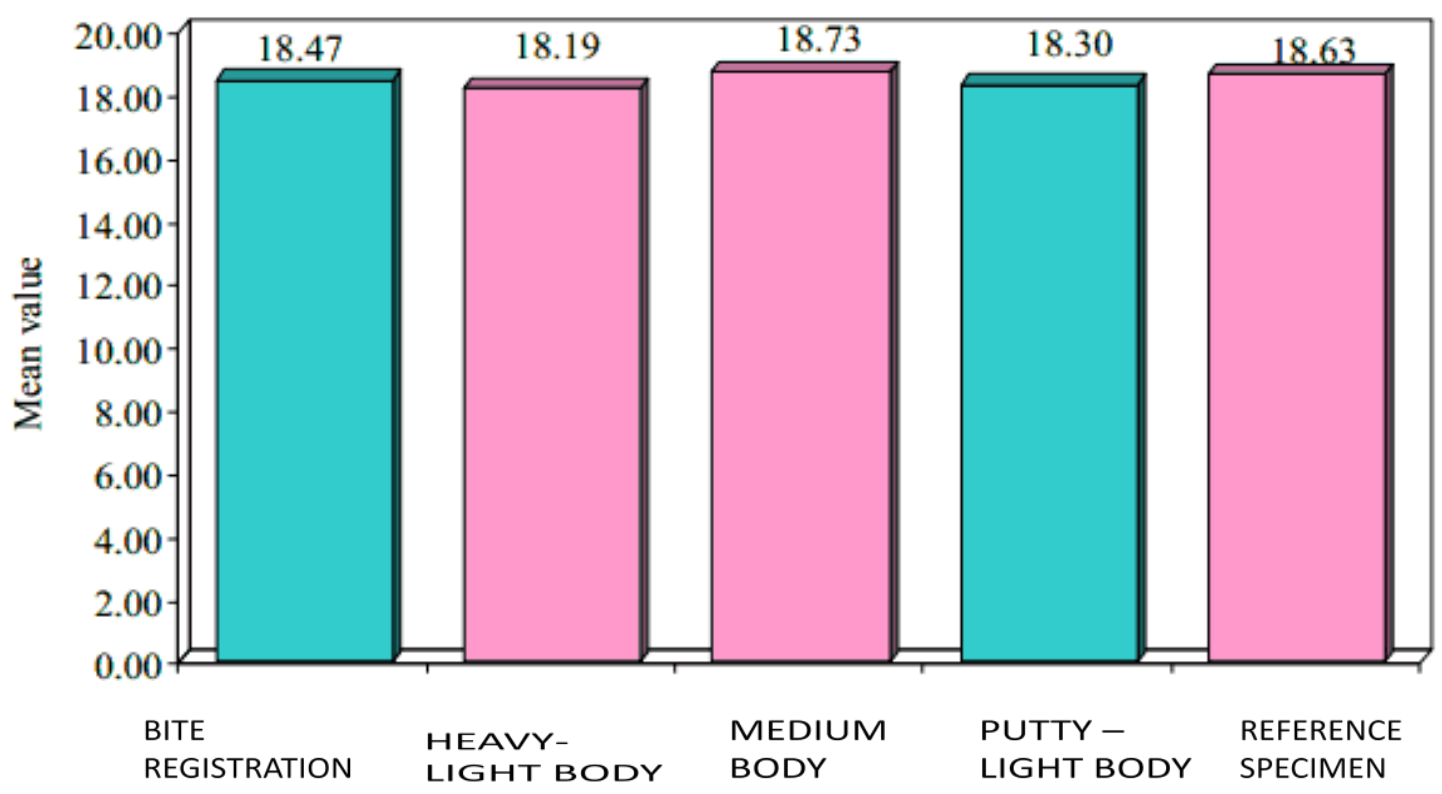

TABLE 4: COMPARISON OF FOUR MATERIALS WITH REFERENCE SPECIMEN IN 15 DEGREE ANGULATED CONDITION (mean values in millimeters) 
least displacement of impression coping during impression procedure while recording the area of interest accurately needs to be evaluated.

The mechanical properties of an impression material, such as accuracy and rigidity, may influence the precision of the impression, the cast, and consequently final framework. ${ }^{6}$

Regarding the direct technique, an impression material should provide sufficient rigidity in order to hold the copings in their position during the removal force application, thus preventing incidental displacements and ensuring a minimal positional distortion between the laboratory components. ${ }^{6}$

In the literature, the addition silicon impression material showed higher yield strength and lower modulus of elasticity. ${ }^{6}$

A parallel positioning of the implants, a condition that is not always clinically achievable because of possible anatomical limitations, eased the removal of impressions probably reducing the distortions of the material.

Distortion may be negatively affected by the non parallel positioning of implants as well as by the presence of physical undercuts (i.e. tooth embrasures, bone deformities), as a higher force is needed affecting the precision of the impressions.

Studies suggest that significant differences in accuracy at 10 and 15 degrees have been noted when four to five implants in use ${ }^{16}$.

Highly filled interocclusal recording materials are expected to exhibit less vertical discrepancies due to reduced setting shrinkage and high resistance to deformation ensuring more accurate fit with the stone model ${ }^{14}$.

On the basis of the recorded data, the null hypotheses were rejected as the implant angulations had a significant effect on the accuracy of the models obtained compared with the reference specimen. Research hypothesis is positive that relationship between implant angulation and the accuracy of implant transfer exist.

Limitations of the present study design were as follows :

I. The measured distortions did not completely evaluate the actual three-dimensional distortion of the impressions and the axial rotations of the components were not detected.
II. The results of the present investigation were limited to a number of two implants and may not be relevant for impressions made in the presence of higher or lower numbers of implants.

III. Path of removal was not standardized as only two implant analogues were positioned in resin blocks with distance of $15 \mathrm{~mm}$ between each analogue.

Clinical trials are necessary to validate the accuracy of impression in angulated implants using various viscosities of impression material.

\section{CONCLUSION}

The angulations of the implants may cause displacement of impression coping during impression procedure because higher forces may be required during impression retrieval.

Within the limitations of this study, the following conclusions were drawn:

1. Putty -light body polysiloxane impression is the material of choice for making impressions of implants which are parallel and angulated upto 5 degrees.

2. Bite registration material-putty-light body polysiloxane impression is the material of choice for making impressions of implants which are angulated at 5- 10 degree.

3. Heavy-light body polysiloxane impression is the material of choice for making impressions of implants which are angulated at 10-15 degree.

\section{REFERENCES}

1. Helvey A Gregg, Elastomeric impression materials: Factors to consider. Compendium of continuing education in dentistry October 2011; 32(8).

2. D.Markovic, et al, The dimensional stability of elastomeric dental impression materials Contemporary Materials, 111 -1(2012): 105-110.

3 Ramakrishnaiah.R, et al, The effect of chemical disinfection, autoclave and microwave sterilization on the dimensional accuracy of polyvinyl siloxane elastomeric impression materials. World Appl, Sci , 17(1);127-132, 2012

4. Vygandas Rutkunas, Kestutis Sveikata, Raimondas Savickas. Effects of Implant Angulation, Material Selection, and Impression Technique on Impression Accuracy: A Preliminary Laboratory Study. The International Journal of Prosthodontics, Volume 25, Number 5, 2012; 512-515 
5. Roberto Sorrentino, Enrico Felice Gherlone, Gaetano Calesini, Fernando Zarone. Effect of Implant Angulation, Connection Length, and Impression Material on the Dimensional Accuracy of Implant Impressions: An In Vitro Comparative Study; Clinical Implant Dentistry and Related Research, volume 12; Issue1 May 2010: 63-76

6. Mpikos P, Kafantaris N, Tortopidis D, Galanis , Kaisarlis G, Koidis P. The effect of impression technique and implant angulation on the impression accuracy of external- and internal-connection implants. Int J Oral Maxillofac Implants. 2012 NovDec; 27(6):1422-8

7. Papaspyridakos P, Lal K, White GS, Weber HP, Gallucci GO. Effect of splinted and nonsplinted impression techniques on the accuracy of fit of fixed implant prostheses in edentulous patients: a comparative study. Int J Oral Maxillofac Implants. 2011 Nov-Dec; 26(6):1267-72

8. Alikhasi $M$, Siadat $H$, Monzavi A, Momen-Heravi F. Three-dimensional accuracy of implant and abutment level impression techniques: effect on marginal discrepancy. J Oral Implantol. 2011 Dec; 37(6):649-57

9. Schwarz MS. Mechanical complications of dental implants. Clinical Oral Implants Research. 2000 Sep;11:1568.Availablefrom:http://dx.doi.org/10.1034 /j.1600-0501.2000.011s1156.x

10. Esposito M, Hirsch J-M, Lekholm U, Thomsen P. Biological factors contributing to failures of osseointegrated oral implants, (I). Success criteria and epidemiology. European Journal of Oral Sciences. 1998 Feb;106(1):527-51. Available from: http://dx.doi.org/10.1046/j.0909-8836..t01-2-.x
11. Papaspyridakos $P$, Chen CJ, Chuang SK, Weber HP, Gallucci GO A systematic review of biologic and technical complications with fixed implant rehabilitations for edentulous patients. Int J Oral Maxillofac Implants. 2012 Jan-Feb; 27(1):102-10

12. Papaspyridakos P, Chen C-J, Gallucci G, Doukoudakis A, Weber H-P, Chronopoulos V. Accuracy of Implant Impressions for Partially and Completely Edentulous Patients: A Systematic Review. The International Journal of Oral \& Maxillofacial Implants. 2014 Jul;29(4):836-45. Available from: http://dx.doi.org/10.11607/jomi.3625.

13. Chai J, Takahashi Y, Lautenschlager EP. Clinically relevant mechanical properties of elastomeric impression materials. Int J Prosthodont. 1998 MayJun;11(3):219-23

14. Herfort TW, Gerberich WW, Macosko CW, Goodkind RJ. Viscosity of elastomeric impression materials. The Journal of Prosthetic Dentistry. 1977 Oct;38(4):396404. Available from: http://dx.doi.org/10.1016/00223913(77)90093-2.

15. Hatzi P, Tzakis M, Eliades G. Setting characteristics of vinyl-polysiloxane interocclusal recording materials. Dental Materials. 2012 Jul;28(7):783-91. Available from: http://dx.doi.org/10.1016/j.dental.2012.04.001

16. Lee H, So JS, Hochstedler JL, Ercoli C. The accuracy of implant impressions: A systematic review. The Journal of Prosthetic Dentistry [Internet]. Elsevier BV; 2008 Oct;100(4):285-91. Available from: http://dx.doi.org/10.1016/s0022-3913(08)60208-5

17. Baig.MR. Multi-unit implant impression accuracy: A review of the literature. Quintessence Int. 2014 Jan;45(1):39-51 